\title{
URBAN MODELLING PERFORMANCE OF NEXT GENERATION SAR MISSIONS
}

\author{
U. G. Sefercik ${ }^{\mathrm{a},{ }^{*}}$, N. Yastiklib ${ }^{\mathrm{b}}$, C.Atalay ${ }^{\mathrm{a}}$

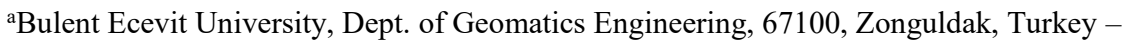 \\ (sefercik,canatalay)@beun.edu.tr \\ bYildiz Technical University, Dept. of Geomatics Engineering, 34220, Istanbul, Turkey - \\ nyastikli@gmail.com
}

\section{Commission III, WG III/2}

KEY WORDS: Cosmo-SkyMed, TerraSAR-X, High Resolution Spotlight, Interferometry, Airborne Laser Scanning

\begin{abstract}
:
In synthetic aperture radar (SAR) technology, urban mapping and modelling have become possible with revolutionary missions TerraSAR-X (TSX) and Cosmo-SkyMed (CSK) since 2007. These satellites offer $1 \mathrm{~m}$ spatial resolution in high-resolution spotlight imaging mode and capable for high quality digital surface model (DSM) acquisition for urban areas utilizing interferometric SAR (InSAR) technology. With the advantage of independent generation from seasonal weather conditions, TSX and CSK DSMs are much in demand by scientific users. The performance of SAR DSMs is influenced by the distortions such as layover, foreshortening, shadow and double-bounce depend up on imaging geometry. In this study, the potential of DSMs derived from convenient $1 \mathrm{~m}$ high-resolution spotlight (HS) InSAR pairs of CSK and TSX is validated by model-to-model absolute and relative accuracy estimations in an urban area. For the verification, an airborne laser scanning (ALS) DSM of the study area was used as the reference model. Results demonstrated that TSX and CSK urban DSMs are compatible in open, built-up and forest land forms with the absolute accuracy of 8 $10 \mathrm{~m}$. The relative accuracies based on the coherence of neighbouring pixels are superior to absolute accuracies both for CSK and TSX.
\end{abstract}

\section{INTRODUCTION}

As it is well known, active synthetic aperture radar (SAR) sensors provide their own illumination and can penetrate clouds by longer wavelength transmitting signals. They are capable of acquiring data both day and night offering rapid mapping (Dell'Acqua and Gamba 2010, Gan et al. 2012). By means of these pros, they were utilized by various scientific applications (Meunier et al. 2001, Smith 2003, Chen et al. 2010, Renga et al. 2011, Zhang et al. 2012) up to date. The most significant paradox for the early SAR imagery was the spatial resolution that directly effects the information content. The first advanced SAR missions such as ERS-1 (1991) and JERS-1 (1992) were only able to provide 20-30 m GSDs in best conditions. 2007 was a revolution year for SAR imaging technology on spatial resolution side with next generation satellites Cosmo-SkyMed (CSK) and TerraSAR$\mathrm{X}$ (TSX). They provide $\approx 1 \mathrm{~m}$ azimuth resolution in high resolution spotlight (HS) mode. In addition, these missions are capable of implementing SAR interferometry (InSAR) to create digital surface models (DSMs) which represent the visible surface (top) of the earth including all terrain and non-terrain formations. With the contribution of the CSK and TSX SAR missions, several three dimensional (3D) earth modelling applications have been performed to date (Weber 2007, Covello et al. 2010, Capaldo et al. 2011, Sefercik, 2013). Despite providing several advantages, interferometric DSMs of CSK and TSX have distortions originating from slant range SAR imaging geometry and sensor characteristics that influence the geolocation accuracy and morphology. However, there is no available study concerning the thorough validation and comparison of CSK and TSX DSMs in the literature. We believe that this study will be a reference for upcoming related works.

\section{STUDY AREA AND MATERIALS}

The study area covers $1 \times 1 \mathrm{~km}$ in the historical peninsula of Istanbul containing four different land classes; open, built-up, road, and forest. The orthometric height in the field reaches up to $70 \mathrm{~m}$. The settlement areas are dominant and include indiscriminate building heights and narrow streets. Figure 1 shows the study area on the co-registered master and slave CSK images.

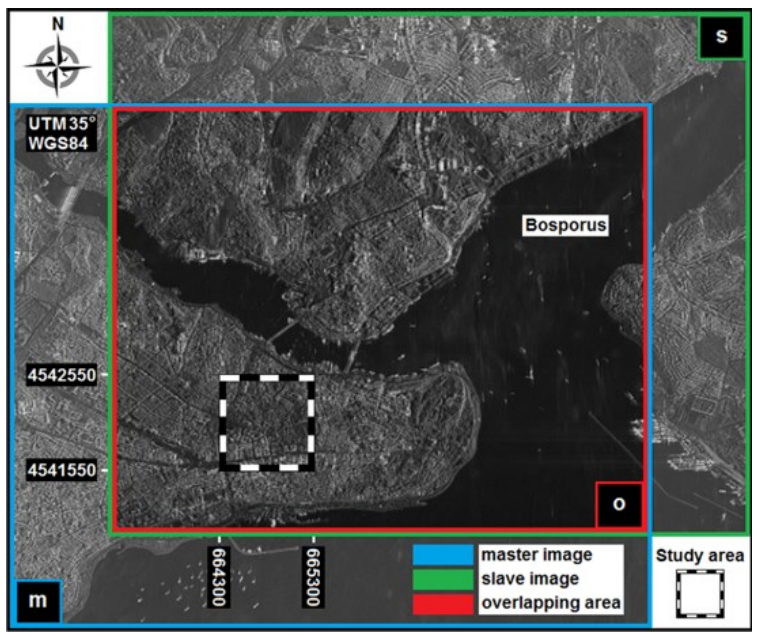

Figure 1. Study area and the distribution of terrain inclination $(\mathrm{m}=$ master CSK image; $\mathrm{s}=$ slave CSK image $)$

The German TSX was launched in 2007 and has 11 days repeatcycle. The CSK mission consists of four low earth orbit midsized X-band SAR satellites constellation that were launched in 2007 and 2008 by the Italian Space Agency and each satellite has 16 days repeat-cycle. For the selection of the most suitable master and slave images (InSAR-pairs), several parameters as overlapping area coverage, temporal baselines and start-stop day- 
times, incidence angles, azimuth and slant range resolutions, imaging and polarization modes were considered on candidate pairs and approximate normal baselines were calculated. As a consequence, most suitable CSK and TSX HS InSAR-pairs that cover the study area were preferred from the archives. The characteristics of selected InSAR-pairs are listed in Table 1.

Table1. Characteristics of CSK and TSX InSAR-pairs

\begin{tabular}{l|c|c|c|c}
\hline \multirow{2}{*}{ Parameter } & \multicolumn{2}{c}{ CSK } & \multicolumn{2}{c}{ TSX } \\
\cline { 2 - 5 } image & $\begin{array}{c}\text { Slave } \\
\text { image }\end{array}$ & $\begin{array}{c}\text { Master } \\
\text { image }\end{array}$ & $\begin{array}{c}\text { Slave } \\
\text { image }\end{array}$ \\
\hline Satellite & CSK-4 & CSK-1 & \multicolumn{2}{c}{ TSX } \\
\hline $\begin{array}{l}\text { Imaging } \\
\text { mode }\end{array}$ & $\begin{array}{c}\text { HS-2 } \\
\text { SLC }\end{array}$ & HS-2 SLC & HS SLC & HS SLC \\
\hline Coverage & $7 \times 7 \mathrm{~km}$ & $7 \times 7 \mathrm{~km}$ & $5 \times 10 \mathrm{~km}$ & $5 \times 10 \mathrm{~km}$ \\
\hline $\begin{array}{l}\text { Acquisition } \\
\text { date }\end{array}$ & $9 / 7 / 2011$ & $29 / 7 / 2011$ & $6 / 10 / 2008$ & $5 / 5 / 2008$ \\
\hline Start time & $16: 07: 52$ & $16: 07: 39$ & $15: 57: 42$ & $15: 57: 33$ \\
\hline Stop time & $16: 08: 00$ & $16: 07: 47$ & $15: 57: 43$ & $15: 57: 34$ \\
\hline $\begin{array}{l}\text { Pass } \\
\text { direction }\end{array}$ & Desc. & Desc. & Ascen. & Asce. \\
\hline Look side & Right & Right & Right & Right \\
\hline $\begin{array}{l}\text { Pixel spacing } \\
\text { (Az) }\end{array}$ & 0.7015 & 0.7029 & 0.8507 & 0.8611 \\
\hline $\begin{array}{l}\text { Pixel spacing } \\
\text { (SR) }\end{array}$ & 0.3520 & 0.3520 & 0.4547 & 0.4547 \\
\hline $\begin{array}{l}\text { Polarization } \\
\text { mode }\end{array}$ & $\mathrm{VV}$ & $\mathrm{VV}$ & $\mathrm{HH}$ & $\mathrm{HH}$ \\
\hline $\begin{array}{l}\text { Incidence } \\
\text { angle }\end{array}$ & $33.93^{\circ}$ & $33.93^{\circ}$ & $41.09^{\circ}$ & $40.98^{\circ}$ \\
\hline
\end{tabular}

\section{METHODOLOGY}

The CSK and TSX DSMs were generated with standard interferometric procedure using one of the most advanced SAR processing software ENVI SARscape 4.3. The selection of suitable InSAR-pairs is the first step of interferometric processing and has a vital importance for the generation of more accurate final interferometric 3D products. To find the optimal InSAR-pair, main baseline parameters as temporal and normal baselines and $2 \pi$ ambiguity height were estimated for candidates. Both satellites are operated with repeat-pass interferometry to produce 3D data and acquires stereo coverage by two passes from the top of study area with slightly different incidence angles. Due to the time interval between the two passes, the changing seasons and climate cause atmospheric de-correlation resulting in noise on the interferogram. To decrease the atmospheric de-correlation effects, InSAR-pairs were selected on the basis of the short temporal baselines. In addition to the temporal baseline, the normal baseline between two SAR antenna positions provided by repeat-pass is one of the most significant parameters in achieving accurate 3D surface determination. If the normal baseline between two SAR antenna positions is over long or over short, the noise increasingly affects the interferogram depending on excessive oblique or perpendicular views and the 3D topographic estimation becomes complicated. Thus, InSAR-pairs which have the optimal normal baseline were preferred to maximize the signal-to-noise (SNR) ratio and the quality of final DSM. This is a similar scenario with the height-to-base ratio $(\mathrm{h} / \mathrm{b})$ in crosstrack stereo optical imagery. At the selection of InSAR-pair, another important parameter is $2 \pi$ ambiguity height between interferometric fringes that limits the maximum measurable step height difference between two neighboring sample points to be less than half the equivalent wavelength of moire fringes (SeungWoo et al. 1998). The lower value for this parameter increases the performance of the generated DSM. Table 2 shows the baseline estimation parameters of preferred InSAR-pair. Regarding the geometry of repeat-pass InSAR, the orthometric height of a ground point is calculated using equation (1); where $B$ is the normal baseline between two antenna positions, $\Delta Z$ is the height of target point $P, H$ is the altitude from the SAR antenna 1 (SAR 1), $\theta$ is the viewing angle from $\operatorname{SAR} 1, \xi$ is the baseline declination, $\lambda$ is the wavelength, $\Delta \varphi$ is the phase difference, $r_{1}$ and $r_{2}$ are the slant ranges between the target point and $S A R 1$ and SAR 2 antennas respectively, and $p$ is 1, 2 (Soergel 2009).

$$
\Delta Z=H-r_{1} \times \cos \left[\xi+\sin ^{-1} \frac{\Delta \varphi \times \lambda}{2 \pi \times B \times p}\right]
$$

Table 2. Baseline estimation parameters

\begin{tabular}{lcc}
\multicolumn{1}{c}{$\begin{array}{c}\text { Baseline estimation } \\
\text { parameters }\end{array}$} & CSK & InSAR-pair \\
\hline Normal baseline $(\mathrm{m})$ & 104.53 & 136.21 \\
Critical baseline $(\mathrm{m})$ & 15099.24 & 15770.57 \\
$2 \pi$ ambiguity height $(\mathrm{m})$ & 71.08 & 45.95 \\
$\begin{array}{l}\text { Doppler centroid and } \\
\text { critical differences }(\mathrm{Hz})\end{array}$ & $-471.54 / 9818.70$ & $154 / 3514.78$ \\
Temporal baseline & 20 days & 154 days \\
\hline
\end{tabular}

In SAR imaging, one of the most significant problems is the speckle noise that reduce the SNR ratio and adversely affect the quality of final DSM. This is a common phenomenon in all signal based imaging systems. The measured ground objects in different forms reflect dissimilar backscattered signals that cause constructive and destructive interferences result in speckles. To solve this problem, multilooking technique (Moreira 1991) was used. Applying this technique, the resolution of output SLC SAR images are reduced multiplying azimuth and range pixel sizes with different multilook factors. However, averaging different multilooks allows to keep the mean of the data and decrease their standard deviation. The square pixels are achieved and azimuth and range pixel sizes are adjusted for output DSM. In this study, the multilooking factors of $3 \times 3$ (please check the parameters in Tab. 1) were used for the azimuth and range directions respectively in accordance with aimed resolution ( $2 \mathrm{~m}$ ) of final DSM.

To delineate the coherence between master and slave images, coherence maps and a coherence histogram (Fig. 2) were generated where the values are situated between 0 (no coherence) and 1 (full coherence). In coherence maps, the light and dark parts represent the high and low coherent regions, respectively. In SAR imagery, the coherence in settled, mainly built-up areas is higher than in areas covered with vegetation (Fischer et al. 2003). Accordingly, the generated coherence maps shows that the built-up parts of the study area are lighter than the other regions. In coherence maps, to determine the coherent parts clearly, a threshold value of ' 0.35 ' was used. Applying this value, sea surface, some parts of roads and vegetated areas are masked as black. As can be seen in Figure 2, except sea surface (under 0.35 coherence), the coherence of selected InSAR-pairs is mostly more than 0.5. The coherence map also used in geometric correction. 

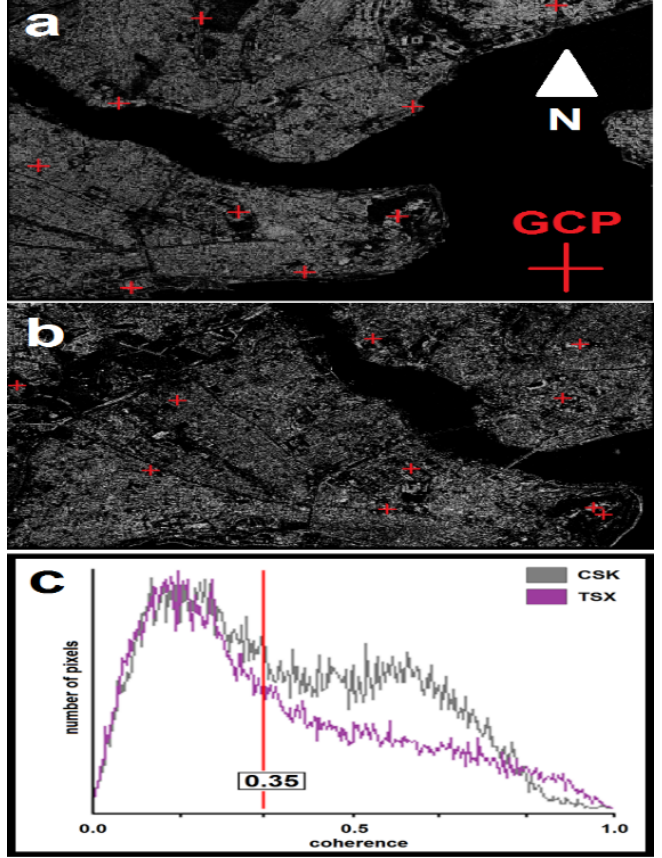

Figure 2. Coherence maps $(\geq 0.35)$ of the CSK (a) and TSX (b) InSAR-pairs including used GCPs for orbital refinement and coherence histogram (c)

The advanced SAR satellites as CSK and TSX have fine orbital geometries however orbital refinement is an essential application to achieve more precise DSMs. At the InSAR processing, the geometric correction does not need ground control point (GCP) measurements on the terrain as in radargrammetry and GCPs (Fig. 2) can be collected from unwrapped phase image and coherence map. In this study, the optimal number of GCPs were collected with radial distribution on lighter details having high coherence. However, one point should not be omitted here; due to layover effect, some of defective objects may seem lighter than surrounding objects because of low incidence angles. These objects should be avoided in GCP collection, otherwise the geometric correction may be inaccurate. To detect these defective objects, histogram drawing is recommended on coherence map where GCP will be established.

\section{RESULTS}

Figure 3 shows the generated 3D CSK and TSX DSMs without an exaggeration. In the Figure, it can be easily interpreted that the TSX DSM is more compatible with reference model derived from airborne laser scanning (ALS) data, produced by Greater Municipality of Istanbul in early 2013 and have $10 \mathrm{~cm}$ vertical accuracy. In addition, the description of roads at the narrow streets between buildings are more satisfactory than CSK DSM.

In the application, the common coordinate system and datum were determined as Universal Transverse Mercator (UTM) $35^{\circ}$ and world geodetic system 1984 (WGS84). In vertical accuracy assessment, the horizontal overlap of tested model and reference model has to be fixed for correct comparison. Since the coordinate transformation from national datum (for reference model) and the horizontal geolocation errors that cannot totally eliminated by geometric correction (for satellite data) cause horizontal offsets between tested and reference models. In the study, the horizontal offsets were determined as $1.8 \mathrm{~cm}$ and 7.5 $\mathrm{cm}$ in X and $4.0 \mathrm{~cm}$ and $-1.4 \mathrm{~cm}$ in Y directions for CSK and TSX respectively by area based cross-correlation and eliminated for $100 \%$ overlap by horizontal shifting.

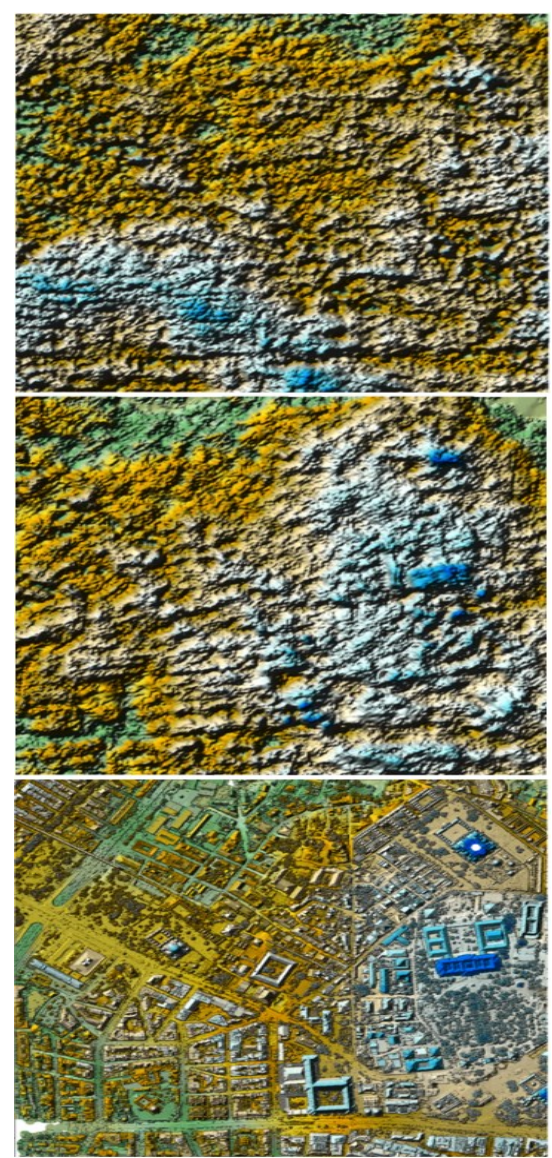

Figure 3. Generated 3D DSMs without exaggeration (CSK $\mathrm{DSM}=$ upper; TSX DSM= middle; reference DSM= lower)

The 3D earth modelling potential of the CSK and TSX DSMs was analyzed calculating absolute vertical accuracies (AVA) and relative vertical accuracies (RVA) on varied land forms showed in Figure 4 with land cover percentages. For validation of tested DSMs, software BLUH version 2012 (bundle block adjustment Leibniz University Hannover) (Jacobsen 2011) was utilized.
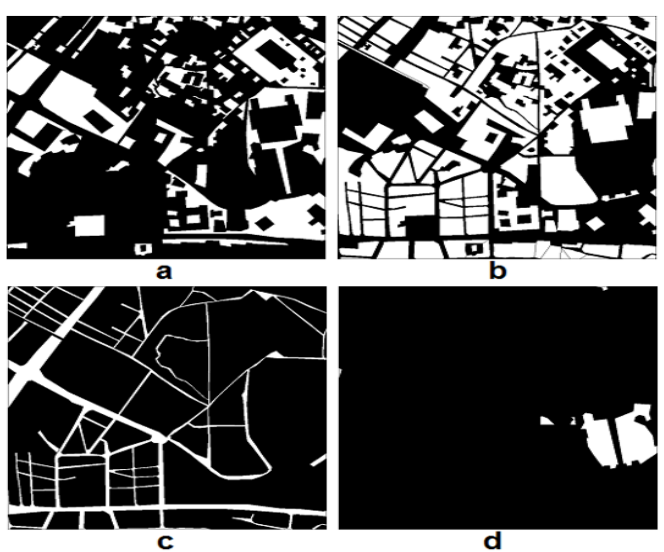

Figure 4. Land forms in the study area

( $a=$ open, $28.10 \%$; $b=$ building, $53.09 \%$; $c=$ road, $14.52 \%$; $d=$ forest, $4.29 \%$ )

The AVA of a DSM can be described using many different criteria. In the study, we defined AVA with the effect of terrain inclination in addition to the constant $\sigma_{\Delta Z}$ as in equation (2); where, $b$ is the multiplication factor of the terrain slope, and 
$\tan (\alpha)$ is the dependency on changing the terrain slope and $\Delta Z$ is the height discrepancies between tested and reference model.

$$
A V A=\sigma_{\Delta Z}+b \times \tan (\alpha)=\sqrt{\frac{\sum \Delta z^{2}}{n-u}}+b \times \tan (\alpha)
$$

Table 3 shows the AVAs of tested DSMs in comparison with the reference ALS DSM including different accuracy criteria. The AVAs of SRTM C-band which was used as a coarse DSM in interferometric processing workflow is also shown in the Table. SRTM C-band results are given only for whole area to avoid misleading results in separate layers considering 3 arcsecond ( 90m) grid spacing.

Table 3. The AVAs of CSK, TSX, and SRTM C-band DSMs against ALS DSM

\begin{tabular}{|c|c|c|c|c|}
\hline $\begin{array}{l}\text { Ref. } \\
\text { DSM }\end{array}$ & $\begin{array}{c}\text { Tested } \\
\text { DSM }\end{array}$ & Layer & $\sigma_{\Delta Z}$ & $\begin{array}{c}\text { Excluded } \\
\text { points } \\
(\%)\end{array}$ \\
\hline \multirow{11}{*}{ ALS } & \multirow{5}{*}{ CSK } & $\begin{array}{c}\text { whole area } \\
(100 \%)\end{array}$ & 9.58 & 0.00 \\
\hline & & $\begin{array}{c}\text { open } \\
(28.10 \%)\end{array}$ & $\begin{array}{c}8.51+1.55 \\
\times \tan (\alpha)\end{array}$ & 0.00 \\
\hline & & $\begin{array}{l}\text { built-up } \\
(53.09 \%)\end{array}$ & 9.70 & 0.00 \\
\hline & & $\begin{array}{c}\text { road } \\
(14.52 \%)\end{array}$ & $\begin{array}{c}10.74+1.57 \\
\times \tan (\alpha)\end{array}$ & 0.00 \\
\hline & & $\begin{array}{c}\text { forest } \\
(4.29 \%)\end{array}$ & 8.40 & 0.02 \\
\hline & \multirow{5}{*}{ TSX } & $\begin{array}{c}\text { whole area } \\
(100 \%)\end{array}$ & 9.33 & 0.00 \\
\hline & & $\begin{array}{c}\text { open } \\
(28.10 \%)\end{array}$ & $\begin{array}{l}8.04+0.95 \\
\times \tan (\alpha)\end{array}$ & 0.00 \\
\hline & & $\begin{array}{l}\text { built-up } \\
(53.09 \%)\end{array}$ & 9.98 & 0.00 \\
\hline & & $\begin{array}{c}\text { road } \\
(14.52 \%)\end{array}$ & $\begin{array}{l}7.25+6.31 \\
\times \tan (\alpha)\end{array}$ & 0.02 \\
\hline & & $\begin{array}{l}\text { forest } \\
(4.29 \%)\end{array}$ & $\begin{array}{c}8.23+1.68 \\
\times \tan (\alpha)\end{array}$ & 0.00 \\
\hline & $\begin{array}{l}\text { SRTM } \\
\text { C-band }\end{array}$ & $\begin{array}{c}\text { whole area } \\
(100 \%)\end{array}$ & 7.30 & 0.00 \\
\hline
\end{tabular}

According to Table 3, the AVAs of CSK and TSX DSMs are compatible in open, built-up, and forest land forms and between $8 \mathrm{~m}$ and $10 \mathrm{~m}$ based on standard deviation of $\Delta Z$ against ALS model. In SAR imagery, due to attenuation of backscattering signals, layover, and shadows of the tall objects, the phase information from narrow streets is noisy in most cases. As a consequence, the CSK results in road layer which mostly represents the narrow streets between buildings, the loss of accuracy is maximum and the AVA of CSK is one and a half times worse than TSX. This result props the visual interpretation of DSMs in Figure 3. The acquisition years of CSK and TSX InSAR-pairs are 2011 and 2008 respectively and the reference ALS DSM is from 2013, this is why the results from open areas are the most reliable indicator since there are possible discrepancies in built-up, road, and forest regions. The AVA of the CSK and TSX DSMs in open areas is determined as approx. $8.5 \mathrm{~m}$ and $8.0 \mathrm{~m}$ respectively. The built-up area is the dominant layer $(53.09 \%)$ and leads the trend of whole area. In this layer, the AVAs of both tested DSMs are approx. $1.5 \mathrm{~m}$ less than open areas. That means, although providing high resolution, because of layover depending on incidence angles, CSK and TSX HS imagery have problems in dense settlement areas consist of indiscriminate building heights and narrow streets.

The maximum accepted $\Delta Z$ between the points of tested model and the reference model is determined as $35 \mathrm{~m}$ and the points, exceeding $\Delta Z$, were marked as excluded points (see Table 3 ). In addition, the points that exceed $\sim 60^{\circ}\left(\tan ^{-1}\right.$ of 2 ) slope to the neighboring points have not been taken for the comparison and marked as excluded points because they may cause problems for the required interpolation. As can be seen on the accuracy Table, in almost entire land forms, the percentage of excluded points is zero and all of points were used in the calculation. Just forest layer in CSK and road layer in TSX have very limited (0.02\%) excluded points depending on low SNR. The distribution of $\Delta Z$ between $\pm 35 \mathrm{~m}$ (max. accepted $\Delta Z$ value) is shown in Figure 5 for open, built-up, road, and forest region.

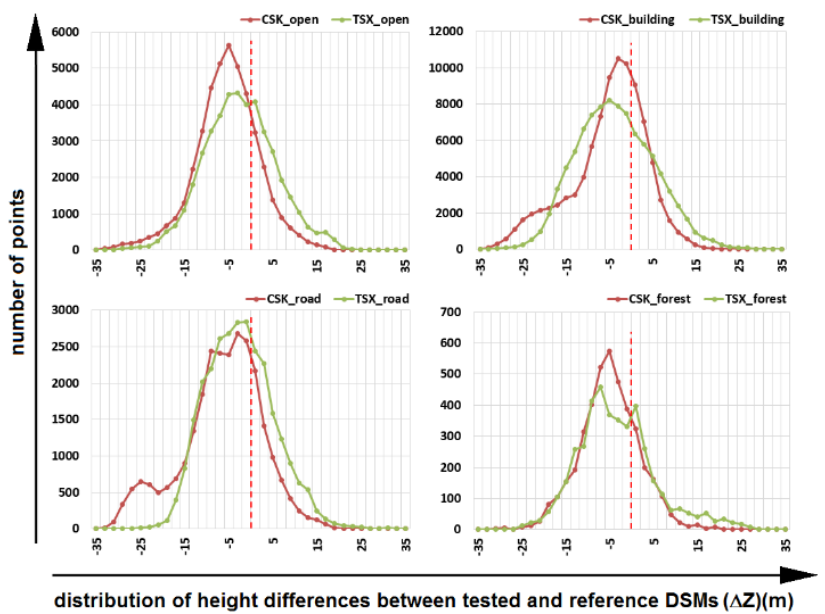

Figure 5. Distribution of $\Delta \mathrm{Z}$ between tested and reference DSMs for each layer

In open area, the $\Delta Z$ distribution of CSK is symmetric however the mode is around $-5 \mathrm{~m}$ where the mode of TSX is close to zero. In built-up area, the mode of CSK is close to zero but a considerable part of points has between $-15 \mathrm{~m}$ and $-25 \mathrm{~m} \Delta Z$. In road, the problems of CSK causes bi-modal distribution where the performance of TSX is quite satisfactory. In forest, the number of analyzed points is less than other land forms that's why the lines are sharper. CSK has a symmetric distribution for this layer and its performance is higher than TSX.

The RVA, that represents the interior coherence of a 3D model, has been calculated based on the correlation between neighboring pixels and depends on the steepness of the terrain and land classes, since image matching algorithms depend on these image features (Reinartz et al. 2006). For each pixel, the neighboring 10 pixels were used to calculate the relative vertical accuracies based on the differences from the reference model. Figure 6 shows the RVA results of the CSK and TSX DSMs considering different land classes.

In principle, the RVAs of the InSAR 3D models are better than their AVAs. Accordingly, all of the layers exhibit similar trends and the numerical results demonstrate that in comparison with AVAs, the interior homogeneity of all layers are higher. The RVAs of land forms in TSX DSM are closer in comparison with CSK's. The absolute vertical error of forest layer still reveals itself at the first pixel as more than $3 \mathrm{~m}$ for both tested DSMs. 
a

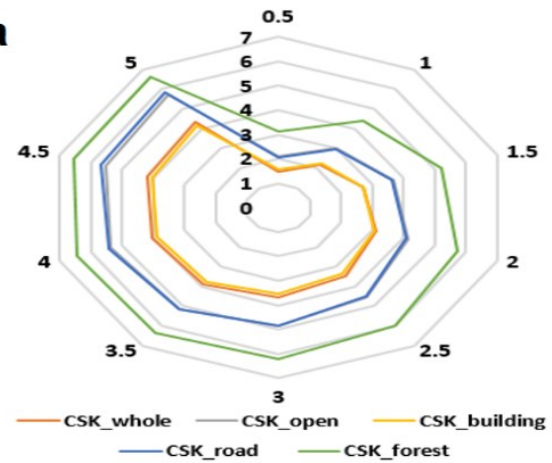

b

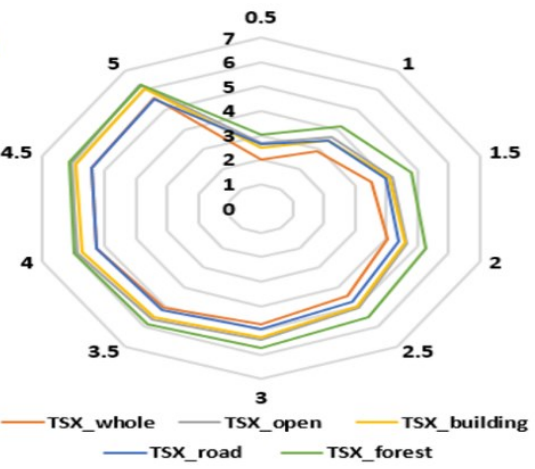

Figure 6. Relative vertical accuracies $(0-7 \mathrm{~m})$ of DSMs for different land forms

$\left(\mathrm{CSK}=\mathrm{a} ; \mathrm{TSX}=\mathrm{b}\right.$; distances from $1^{\text {st }}$ to $10^{\text {th }}$ pixel $\left.=0-5 \mathrm{~m}\right)$

\section{CONCLUSION}

This study reports the performance comparison of DSMs generated from revolutionary SAR satellites CSK and TSX's HS imagery on the basis of a reference ALS DSM. The comparison was performed in Istanbul, Turkey where the varied land forms are available. The most convenient InSAR-pairs were selected considering baseline estimation parameters. The DSMs were evaluated by statistical and visual approaches using several accuracy criteria. The AVA and RVA were calculated as the basic accuracy metrics and the vertical accuracies against a reference model and neighbouring pixels for each DSM were introduced separately. The CSK, TSX, and the reference data were acquired in different years which are why the data from open area is the most reliable land form foreseeing possible discrepancies in built-up, road and forest regions. Furthermore, the dependency of the accuracy on the terrain slope has to be acknowledged. The AVA of CSK and TSX DSMs in open areas is calculated as approx. $8.5 \mathrm{~m}$ and $8.0 \mathrm{~m}$ based on $\sigma_{\Delta Z}$ respectively. Road is the most problematic layer for CSK DSM due to attenuation of backscattering signals from the narrow streets between buildings, layover, and shadows of the tall objects which cause low SNR. As a consequence, the AVA of CSK is one and a half times worse than TSX in road layer. Regarding AVA results, both tested DSMs can be utilized as the height component for the generation of $1 / 50000$ scaled true ortho-images and related vector topographic maps considering NDEP instructions.

\section{ACKNOWLEGMENTS}

We would like to thank Bulent Ecevit University to support CSK InSAR-pair with the Scientific Research Project 2013-4791226602 . We are also grateful to the Metropolitan Municipality of Istanbul for supplying the reference model.

REFERENCES
Capaldo, P., Crespi, M., Fratarcangeli, F., Nascetti, A., and Pieralice, F. (2011). High-resolution SAR radargrammetry: a first application with Cosmo-SkyMed Spotlight imagery. IEEE Geoscience and Remote Sensing Letters, 8(6), pp. 1100-1104, doi:10.1109/LGRS.2011.2157803.

Chen, F., Lin, H., Yeung, K., and Cheng, S. (2010). Detection of slope instability in Hong Kong based on multi-baseline differential SAR interferometry using ALOS PALSAR data. GIScience\&Remote Sensing, 47(2), pp. 208-220, doi:10.2747/1548-1603.47.2.208.

Covello, F., Battazza, F., Coletta, A., Lopinto, E., Fiorentino, C., Pietranera, L., Valentini, G., and Zofolli, S. (2010). CosmoSkyMed an existing opportunity for observing the earth, Journal of Geodynamics, 49(3-4), pp. 171-180, doi: 10.1016/j.jog.2010.01.001.

Dell'Acqua, F., and Gamba, P. (2010). Rapid mapping using airborne and satellite SAR images, radar remote sensing of urban areas, Remote Sensing and Digital Image Processing, Edited by Uwe Soergel, ISBN 978-90-481-3750-3, pp. 4968.

Fischer, P., Perski, Z., and Wannemacher, S. (2003). Radar Backscatter and Coherence Information Supporting High Quality Urban Mapping. Proceedings of Fringe 2003 Workshop, Frascati, Italy, December $1-5$.

Gan, T. Y., Zunic, F., Kuo, C. C., Strobl, T. (2012). Flood mapping of Danube River at Romania using single and multidate ERS2-SAR images, International Journal of Applied Earth Observation and Geoinformation, 18, pp. 69-81, doi:10.1016/j.jag.2012.01.012.

Jacobsen, K. (2011). Bundle block adjustment Leibniz University Hannover, Program System Manual. Institute of photogrammetry and Geoinformation, Hannover, Germany.

Meunier, F., Meunier, J., and Cavayas, F. (2001). Synthetic aperture radar image of agricultural fields with surface drainage network: simulation and spatial information retrieval, Optical Engineering, 40(10), pp. 2319-2330, doi:10.1117/1.1403450.

Moreira, A. (1991). Improved multilook techniques applied to SAR and SCANSAR imagery, IEEE Transactions on Geoscience and Remote Sensing, 29(4), pp. 529-534, doi:10.1109/36.135814.

NDEP (National Digital Elevation Program) (2004). Guidelines for Digital Elevation Data, Version 1.0. May 2004, http://www.ndep.gov/

NDEP_Elevation_Guidelines_Ver1_10May2004.pdf.

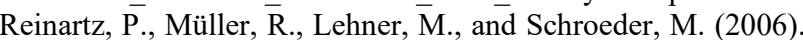
Accuracy analysis for DSM and orthoimages derived from SPOT HRS stereo data using direct georeferencing. ISPRS Journal of Photogrammetry and Remote Sensing, 60(3), pp. 160-169, doi:10.1016/j.isprsjprs.2005.12.003.

Renga, A., Graziano, M. D., D'errico, M., Moccia, A., and Cecchini, A. (2011). SAR-based sea traffic monitoring: a reliable approach for maritime surveillance, Proceedings of SPIE. 8179, SAR Image Analysis, Modeling, and Techniques XI $81790 B$, October 6.

Sefercik U. G. (2013). Productivity of TerraSAR-X 3D Data In Urban Areas: A Case Study In Trento, European Journal of Remote Sensing, Vol: 46, pp. 597-612, doi: 10.5721/EuJRS20134635.

Seung-woo, K., Jung-taek, O., Moon-sik, J., Yi-bae C. (1998). Two-frequency phase-shifting projection moire topography, Proc. SPIE 3520, Three-Dimensional Imaging, Optical Metrology, and Inspection, 4(36), November 20, doi:10.1117/12.334348.

Smith, A. (2003). Gas pipeline monitoring in Europe by satellite SAR, Proceedings of SPIE. 4886, Remote Sensing for 
Environmental Monitoring, GIS Applications, and Geology II 257, March 14.

Soergel, U. (2009). Radar remote sensing lecture notes, Hannover, Germany, April.

Weber, M. (2007). TerraSAR-X and TanDEM-X: reconnaisance applications. Proceedings of Recent Advances in Space Technologies, 2007. RAST '07, 3rd International Conference, Istanbul, Turkey. pp. 299-303.

Zhang, F., Xu, M., Xie, C., Xia, Z., Li, K., and Wang, X. (2012). Forest and Deforestation Identification Based on Multitemporal Polarimetric RADARSAT-2 Images in Southwestern China. Journal of Applied Remote Sensing, 6(1), pp. 063527, doi: 10.1117/1.JRS.6.063527. 